\title{
Research on Chinese University Governance for Open Education
}

\author{
Yun Yuan \\ Department of Development and Planning, \\ Northwestern Polytechnical University \\ Xi'an, P.R.China \\ yuanyun@nwpu.edu.cn
}

\author{
Xingqiang Du \\ School of Electronics and Information, \\ Northwestern Polytechnical University \\ Xi'an, P.R.China \\ dxqqqqq@nwpu.edu.cn
}

\begin{abstract}
Reform on Chinese universities' governance mechanism and structure is not only the respond to the trend of streamlining government and delegating authorities, but also the way to tackle new challenges on universities, mainly from the perspective of open education. Suggestions on governance structure are made based on a stakeholder analysis. With the development of open education, external stakeholders have stronger influence on Chinese universities' governance. Decide>Plan->Act->Evaluate (DPAE) cycle is proposed for making possible changes for governance mechanism and structure, especially when enhancing external stakeholders' contributions to the development of Chinese universities.
\end{abstract}

Keywords-university governance; open education; stakeholder analysis

\section{INTRODUCTION}

With the development of higher education, universities are facing to various new challenges, such as internationalization of education, web-based teaching and learning, university marketing and branding, and global competition of talent recruitment and retention. The key to success is doing the right things and do things right, which is often to be ensured by the governance of universities. This explains why governance mechanism and structure of universities remains as one of the hottest topics for Chinese higher education.

In China, university governance serves for the purpose of dealing with the essential relationship with the party and the government, and the society. The party and the government have the major impact on the management and operation of universities by issuing regulations, allocating resources, monitoring progress and etc. Universities take their responsibility for operation. The society provides the support and feedback on the development of universities in various ways. Nowadays, more and more NGOs start to evaluate and rank universities according to their performance and the results are likely regarded as certain guidelines for teenagers to apply for their ideal universities or for employers to recruit qualified candidates from graduates.

Furthermore, an effective university governance mechanism and structure also shapes scientific research and teaching management, administrative management, human resource management, and schooling system management, etc. Meanwhile, it deals with different powers and interests from various groups within the university, mainly balancing academic power and administrative power. Eventually, the governance mechanism and structure facilitates and supports the university to achieve its goal by combining and optimizes all the resources gathered.

\section{OPEN EDUCATION'S CHALLANGES ON UNIVERSITY}

Open education is to broaden access to the learning and training traditionally offered through formal education systems. One aspect of open education is seeking to eliminate barriers to entry, which flourishes distance learning programs like elearning, MOOC and Open Courseware [1]. Another aspect is developing and adopting open educational resources. With more and more resource, techniques, applications and social powers finding their ways into universities in different means, university governance and management should also respond to these new challenges and demanding requests from students, parents, job market, society and government.

With the further development of open education in China, the government tends to give more power back to universities and get them motivated better. The pattern of the conventional 'power' game changes substantially. This leads to the fact that universities undertake more responsibility and initiatives for their success than before, which influences Chinese university governance mechanism and structure accordingly.

\section{Current Status of University GovernanCE}

In general, the governance mechanisms for universities in Europe or the USA often take the form of common governance or shared governance. A university is a community, in which each one has right in decision making, plays the role independently and coordinates with each other on university affairs. Powers and responsibilities are shared. External and internal stakeholders hold their own interests and have certain needs to meet. Therefore, university governance is missioned by reflecting and implementing a common commitment made by internal faculty and students and external interested parties.

Delft University of Technology is one of universities with such a governance mechanism and structure. The board of overseers is the supreme authority of the university, supervising the administration and operation of the university. It has rights to make suggestions to the board, and also ensures 
the board to obey the laws and regulations. The government controls and influences universities via the board of overseers, also saves the space for universities' autonomy. The board of overseers keeps the university on the right track to meet the demands of the society and the nation's expectations by supervising and providing suggestions instead of interfering the university's management and operation directly. The board is the top administrative organization of the university, which takes care of the overall management and operation, and reports to the board of overseers. The chairman and the vice chairman of the board in general are not the staff of the university. The president and the vice chancellor of the university are members of the board, however, whose power is restricted by the chairman and the vice chairman of the board.

Effective and transparent communications are crucial for the shared governance of a university. California University believes decisions affecting university constituencies are based upon mutually supportive and respectful dialogue, which involves broad and unending two-way communication. University authorities have a responsibility to inform potentially affected constituencies and provide them sufficient opportunity for dialogue before decisions are reached. All such constituencies have the opportunity to influence decision making and retain the right to receive a reply [2].

Being compared with European and American universities, the governance mechanism and structure for most Chinese universities has been developed by an approach somewhat different from European and American modes. The fundamental power of university comes from the party and the governmental organizations, which actually determines today and the future of university governance mechanism and structure in China. The university governance mechanism or structure is regulated by the policies and laws issued by the party and the government. In other word, power for governance and management is granted by the party and the government for public universities in China. Hence, it is not difficult to understand major changes or reforms on universities' governance mechanisms and structures are used to be pushed forward by the party and the government, instead of directly by the inherent development needs of universities [3].

The fast-growing China calls for deepening streamlining government and delegating authorities, which provides more opportunities and possibilities for universities to explore and improve the governance mechanism and structure, together with party, the government and other stakeholders. The "Double first-rate" plan, which is regarded as one of the most important strategic development plans for Chinese higher education in the coming few decades, stimulates Chinese universities to focus more on the excellence. In order to become world-class universities, Chinese universities are proactive for getting more endorsement from the society. Traditional managerial mindset and governance approach cannot fully meet these needs of new challenges and changes. Some parts of the current governance mechanism and structure are not compatible and adaptive to the dynamic changing needs, therefore, are subjected to be reexamined and reconsidered.

\section{STAKEHOLDER ANALYSIS OF CHINESE UNIVERSITIES}

In view of existing governance mechanism and structure for, Chinese universities take having autonomy and obtaining social resources as more difficult challenges than dealing with internal conflictions and motivating staff.

Research has proved that key stakeholders have strong impacts on the university's governing and management. The key is to balance different interests of key stakeholders and enhance the sustainable growth of a university by governance and management. Therefore, a stakeholder-analysis approach is taken in order to understand real issues in the current Chinese university governance mechanism and structure, as is shown in figure 1 .

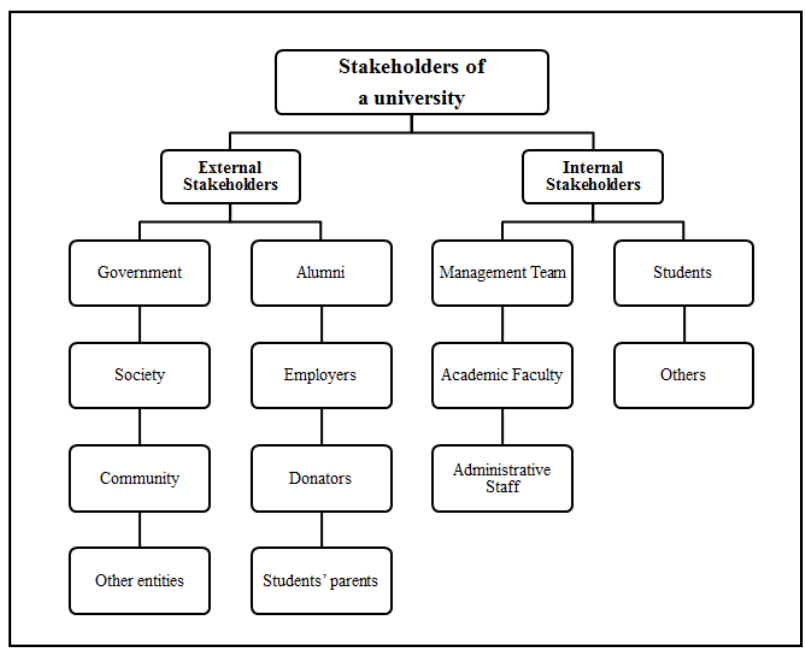

Fig. 1. Stakeholders of a university

In China, the party and the government, as the key investors of public universities, manage universities at the macro-level. Education administrative departments, including Ministry of Education, are the representatives of the party and the government, which fulfill the authorized responsibilities. Presidents of universities are appointed by the party and the government. Managerial and administrative staffs are recruited at the university-level. Professors, lecturers and researchers provide the education service for the society. Students and their parents are consumers of higher education. Donators are contributors from the finance or infrastructure wise. Enterprises or employers are beneficiaries of the higher education service. All these stakeholders differ on their interests and powers of governing or influencing universities, which is also reflected in university governance mechanism and structure to enable stakeholders to get involved into the decision-making process for important university matters. The core is to formulate the process of transferring or allocating different powers and resource and match them with the strategic plan and its execution.

The voice of external stakeholders, including employers, donators, students' parents and alumni, has been amplified than before with the development of open education. These externals are actively involved in the development of universities, also asking for stronger presence in the governance mechanism and structure to ensure their rights for 
their own interests. External stakeholders influence the competition environment of universities by regulating different policies of enrolling students, categorizing majors and academic disciplines, shifting tuitions, changing investment, adjusting employment, evaluating or commenting on universities' performance, etc. Hence, it is important for universities to build closer connections with these externals, not only bridging trends and needs with internal operation, but also absorbing more resources and wisdom from the world out of universities [4].

For a university in China, the party committee, the president's office and administrative organizations have major impact on the university's leadership and management. Power conflictions between academic groups and administrative groups are often unsolved. Moreover, schools are not willing to take full initiatives to carry on comprehensive reform due to insufficient authority given by the university, or schools' incompetence of handling powers and responsibilities transferred. The arguments between the university and its schools often are not only about the power list and the negative list of power, but also about the schools' performance appraisal and incentive programs.

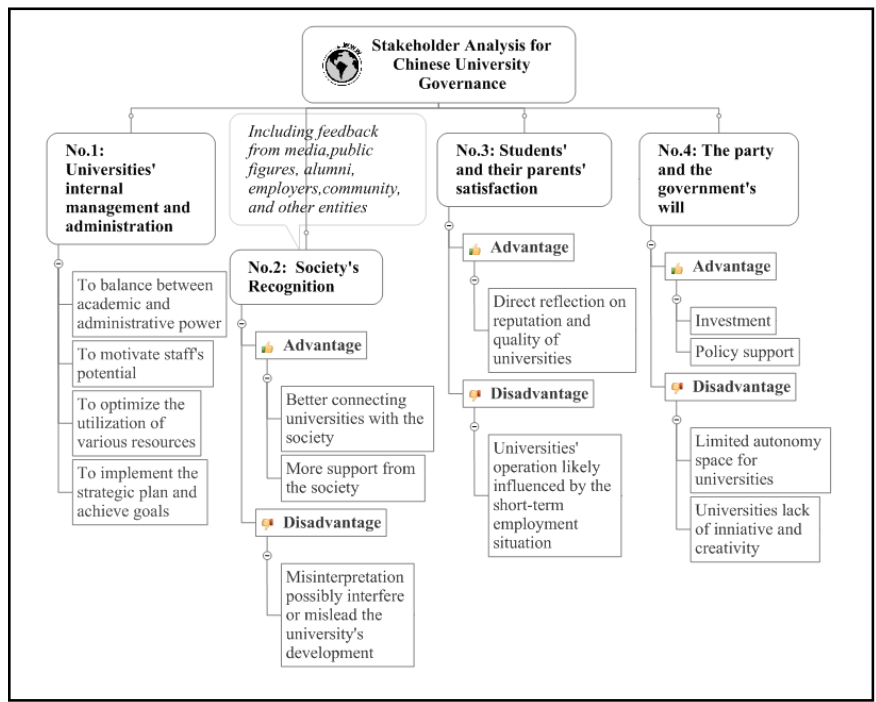

Fig. 2. Analysis of stakeholders for Chinese university governance

A further analysis on key stakeholders of universities is illustrated by Figure 2. Internally, the governance mechanism and structure is mainly to get a balance between academic and administrative power, to motivate staff's working spirit and potential, and to optimize the utilization of various resources in order to achieve goals of the university. Externally, recognitions and evaluations provided by media, public figures, alumni, employers, community and other entities are closely related to the support that universities can get and their reputations. Sometimes, the feedback can be interpreted incorrectly, and the misinterpretation interferes or misleads the development of the university. Meanwhile, students' and their parents' satisfaction becomes a more important driving force for the development of universities, though, likely being influenced by the short-term job market. Aligning the development with the party and the government's will is important for universities to obtain the investment and policy support, however, such a central power control from the government also limits universities' autonomy space in reality.

The success of a university is dependent on the joint efforts made by its stakeholders. Whether all parties have certain goals in common, whether each has its own responsibilities and authorities agreed upon, whether communications are effective and transparent enough, whether actions are aligned with the strategic plan, and whether resources needed is gathered sufficiently, whether results meet the expectations, whether all benefits and interests can be shared in an acceptable way, these are all important aspects to consider when designing the governance mechanism and structure of a university [5].

\section{NeW Practices of CHINESE UNIVERSITIES GOVERNANCE}

China Southern University of Science and Technology has been active in practicing on its governance reform. It tends to divide power boundaries for the government, the university, the society, and other external stakeholders explicitly. It also defines the internal administrative and academic power clearly. The members of the board include representatives from the government, the society, the president and his management team, and the academic staff in the university, etc. All the key stakeholders make decisions on important university affairs together and stay in a balanced status with the working efficiency improved, resource allocation optimized and goals well achieved [6]. The principle of shared governance is applied, by which external and internal stakeholders get involved into the decision-making process and become members of relevant organizations in the university. Administrative and academic units, representatives from governing bodies, including administrators, faculty, staff and students work together, thanks to open communication, transparency and mutual trust [7].

Reform on the governance mechanism and structure of Chinese universities often has following features. Firstly, since the development of universities has been changed by the supply driven to demand driven, universities tend to match the dynamic needs better by adjusting the governance mechanism and structure. Secondly, university governance becomes more complicated because more social powers and external bodies tend to pursue their interests as important stakeholders of universities. Such a multi-stakeholder governance system is a community demanded for developing common strategic plan, sharing common mission and vision, making joint efforts to meet budget requirements and priorities, implementing strategic planning, developing curriculum and program, taking care of faculty matters, mediating conflictions and building campus-community relations. Hence, the governance mechanism and structure change from a top-down approach to a shared-governance approach which is coordinated by multiple centers.

\section{SUGGESTIONS AND CONCLUSIONS}

In general, the governance of a university has its impact on the decision-making, planning, implementing and evaluating of the university affairs, especially for those important. Hence, these four crucial aspects or phases are summarized as Decide$>$ Plan->Act->Evaluate (DPAE cycle), shown in Figure 3. With 
the further development of open education, the ambitious Chinese "Double first-rate" plan, the party and the government's unique role on the development of Chinese universities, the governance mechanism and structure of Chinese universities needs to make major adaption to these trends and challenges.

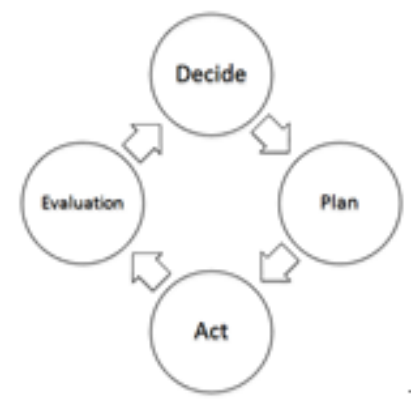

Fig. 3. University governance changes for DPAE cycle

External powers influence and nurture the development of a university through the whole DPAE cycle. In the decisionmaking process, information, opinions, suggestions, requests and possible support from the external bodies are well investigated, explored, reviewed and considered. Once the right decisions are made, specific plans are to be agreed by internal stakeholders and relevant external stakeholders, especially for those involving resources and output from and for externals. During the implementation phase, actions taken are not isolated from the externals. Good alignments on actions by universities and their external partners can improve the efficiency and quality. Evaluations are not simply only done by universities themselves and the governmental organizations. More and more NGOs and evaluation or ranking entities get involved into performance evaluations of universities as well. These changes have profound and meaningful impact on the governance of Chinese universities in a positive way. Reform on mechanism and structure of university governance adapts to and also enhances the development of open education in China.

\section{ACKNOWLEDGMENT}

On the completion of this paper, authors would like to appreciate the sponsorship of Northwestern Polytechnical University Policy Research Funding Project ZYY201510.

\section{REFERENCES}

[1] https://en.wikipedia.org/wiki/Open_education.

[2] http://www.calu.edu/about-us/shared-governance.

[3] Bie Dunrong, "On university Governance in China", Shandong Higher Education, P1-P7, No.2, 2016, General No.27 (In Chinese).

[4] Liu Zongrang, "University strategy: influence and management of stakeholders", Higher Education Exploration, P19-P23, No.2, 2010 (In Chinese).

[5] Zhu Peng, "Research on construction of management system for collaborative innovation centers", Higher Education Exploration, P15P18, No.3, 2013 (In Chinese).

[6] Zhang Yifei, $\mathrm{Hu}$ Yong, "An analysis of the framework and characteristics of University Governance: a case study of Southern University of Science and Technology, China Electric Power Education", P5-P6, No.23, 2012, General No.246 (In Chinese).

[7] "Why shared Governance", David Bejou, http://www.linkedin.com/pulse/why-shared-governance-david-bejou. 